\title{
MODERN PROCEDURES USED IN CLEANING OLD, ILLEGIBLY AND BLACKENED ICONS
}

\author{
Silvea Pruteanu ${ }^{1}$, Ion Sandu ${ }^{1,2}$, Viorica Vasilache ${ }^{1,2}$
}

Key words: cleaning procedures, washing tests, solvents, deterioration and degradation effects.

\begin{abstract}
In order to restore the original aesthetic aspect, to improve the state of the age patina and of the gold halo, similar processes are required. The cleaning process is one of the most important aspects for an artwork and is considering a series of deteriorations and degradations, like dirt deposits (clogged or unclogged) opalescent varnish, colors blackening, burns, blisters, gaps (missing ground, painting layer or varnish). This step in the restoration process includes physical and mechanical proceedings like dusting (with a vacuum), brushing (with a brush), scraping (with a scalpel), removal or polishing etc. The scalpel and the milling process are rough unconventional means that are used only in exceptional cases. The wet cleaning of dirt includes classic washing processes, with water or other complex systems of organic solvents (emollients, surface additives or surfactants, mixtures of solvents). Cleaning the clogged dirt deposits with unconventional methods can be done by means of electronic laser, ion and thermal exchange or ultrasounds. Laser cleaning is often used in removing unwanted dirt deposits from different layers of the art piece. A lot of attention goes towards the controlled elimination of the exterior protection layer (varnish), which can be photo- degraded and oxidized by atmospheric exposure. Visual analysis, with enlargers (OM, SEM, AFM etc.) combined with transmission or penetration techniques (radiography, endoscopy, X-ray diffraction etc.) provides information on the superficial structures of the art work. In order to determine the modifications of the desiccant oils, SEM was used to observed the changes in the morphology of the oil painting layers. Gas chromatography/mass spectrometry (GC/MS) can be used to detrmine detergent residues on the painting layer.
\end{abstract}

\footnotetext{
1 „Al. I. Cuza” University, ARHEOINVEST Platform, Blvd. Carol I 11, 700506, Iasi, Romania

2 Romanian Inventors Forum, Str Sf. Petru Movila 3, L11, III/3, 700089, Iaşi, Romania
} 


\section{Introduction}

The removal of the outer protection layer (photo-degraded and chemically altered by assisted oxidation of acid base varnish) in a controlled way gets a lot of attention in the field of scientific conservation [8-13]. When talking about conservation, the original state of the painting is extremely important, the integrity of the object being respected and kept for as long as posible. Part of assessing the effectiveness of cleaning is based on the necesity to establish the original cromatic balance and to identify the original paint version and other distinct interventions which distort the image, like paintings over the varnish layer [1, 3, 5, 10-11]. The difficult part begins when some layers have suffered irreversible physical and chemical alterations. Furthermore, the inconsistencies of previous cleanings results in a imbalance in some areas, which, even if there are completely cleaned aren't so different by the areas that are still clogged with dirt. The cleaning system and the intervention methods must by chosen after taking into consideration chemical and physical nature of the materials that are to be removed and the sensitivity of the original ones [6-8, 12-14]. The cleaning interventions are assisted by surface analysis with enlargers, like optical and electron microscopy (TEM, SEM, AFM), IR reflectography, UV, X-ray fluorescence, FTIR etc.) and also by transmission or penetration techniques, like radiography, endoscopy, X-ray diffraction etc. [15-18] which allow the gathering of information about superficial structures, their nature, their interaction with painting materials etc..

In this sense, this paper takes into study two old icons, used in liturgical rituals that cannot be exposed to the public in collections or museums due to their poor conservation state. The deposits on these two icons were first analyzed by OM and FTIR, in order to point out the modifications of the varnish and desiccant oils by observing the changes in their morphology. These operations take into considerations a series of aspects like the value of the artifact, the nature of the materials used, the deterioration and degradation evolutionary effects, and also the nature and the aggression of the dirt and dirt deposits (clogged dirt). These deposits lead to varnish opalescence, color blackening which combined with burns, blisters and peelings of the painting and varnish layer, which are affecting the integrity and the aspect of the icon, leading to the removal of the art work from the liturgical circuit. The cleaning of dirt includes dry physical and chemical procedures, wet enzymatic techniques and thermal processes like laser pyrolysis. The first group of procedures contains basic actions like dusting (with a vacuum), brushing, scraping (with a scalpel), wiping or dry polishing (in case of fat deposits - wax, tar, paint or other fat materials). The most frequent solution is the usage of classic cleaning solutions with water or other complex systems of organic solvents (emollients, surface additives or surfactants, mixtures of solvents) [2, 4, 7]. A lot of inorganic pigments are oxides, rich in atoms that easily give electrons. 


\section{Experimental part}

Two old icons, one from the XVIII-th century, with the Ascension of the Virgin Mary into Heaven, and the other from the XIX-th century with four registers presenting the Pentecost (Jesus talking to the disciples, Resurrection, Pentecost and Ascension), both painted in neoclassic style, with gold halos were taken into study.

The first icon is part of a private collection (Ascension of the Virgin Mary into Heaven, on lime wood support, in oil) while the second icon belongs to Dobrovăţ monastery (lime wood support, in egg tempera), both being done by anonimous authors (Fig.1 a, b).

The icons have a poor conservation state as a result to the exposure to several physical, chemical, microbiological, climate factors (temperature, humidity, light) age, and improper storage conditions, prolonged exposure in unhealthy conditions. The two painting layers have deep gaps, spread evenly on the surface, cracks and detachments, due to some dimensions modifications and dehydration (Fig.1 a, b). The wood panels have missing pieces (from the frame of the first icon and from the upper side of the second one) and cracks that appeared because of the nails used to hook up the icons. Through UV, IR and visible reflectography, both the front and the back of the icons were analyzed and a series of evolutionary deteriorations and degradations of the painting and polychrome layer and of the support were identified. Traces of mechanical impacts, multiple small gaps and fly holes were observed (Fig. 1a, b).
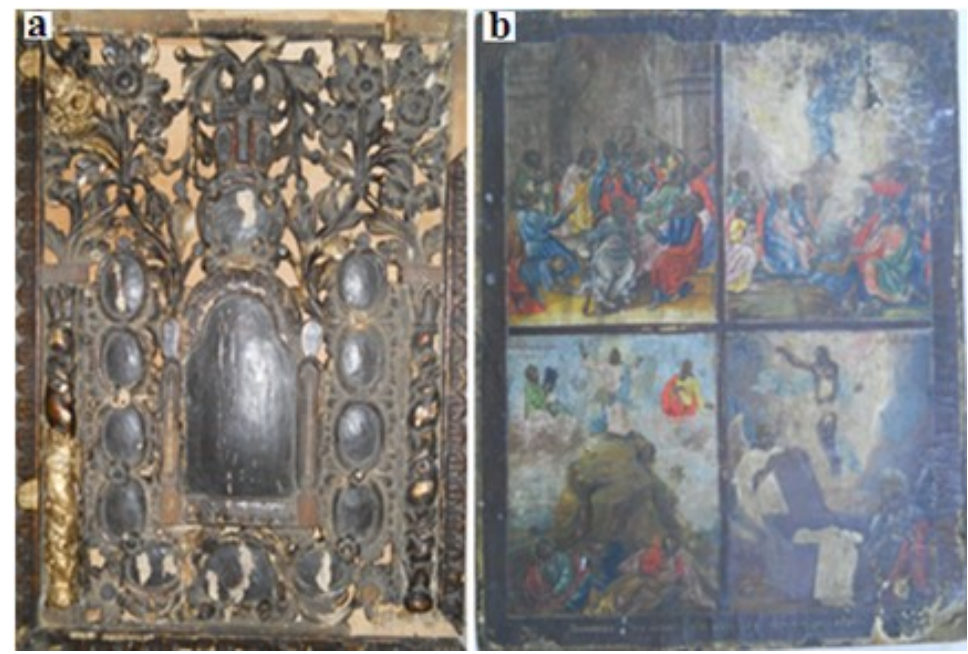

Fig.1. a) Ascension of the Virgin Mary into Heaven;

b) Jesus talking to the disciples, Resurrection, Pentecost and Ascension; 
The first icon shows a scene from Orthodox Christianity Ascension of Virgin Mary into heaven, surrounded by the eight smaller and circular icons, four on the right and four on the left, which are framed in an embroidery carved wood with floral decorations, all kept together in a large narrow sculpted frame. The upper piece of the frame is missing entirely, also a quarter of the right frame. Both the painting layer and the polychrome surface of the painting are covered by a shiny glassy crust, which has accumulated black dirt, heavily clogged and on the sculpted embroidery thick layer of matte powder can by seen with the naked eye. The icon has small uneven deep gaps (all the way to the wood support, in all the painted areas), cracks, exfoliation, detachments of the polychrome layer and dimensional variations due to the dehydration. It also suffers from loss of the embroidery carved wood that surrounds the central icon, missing pieces from the frame, alteration caused by nails use to fix the icon (Fig.1.a).

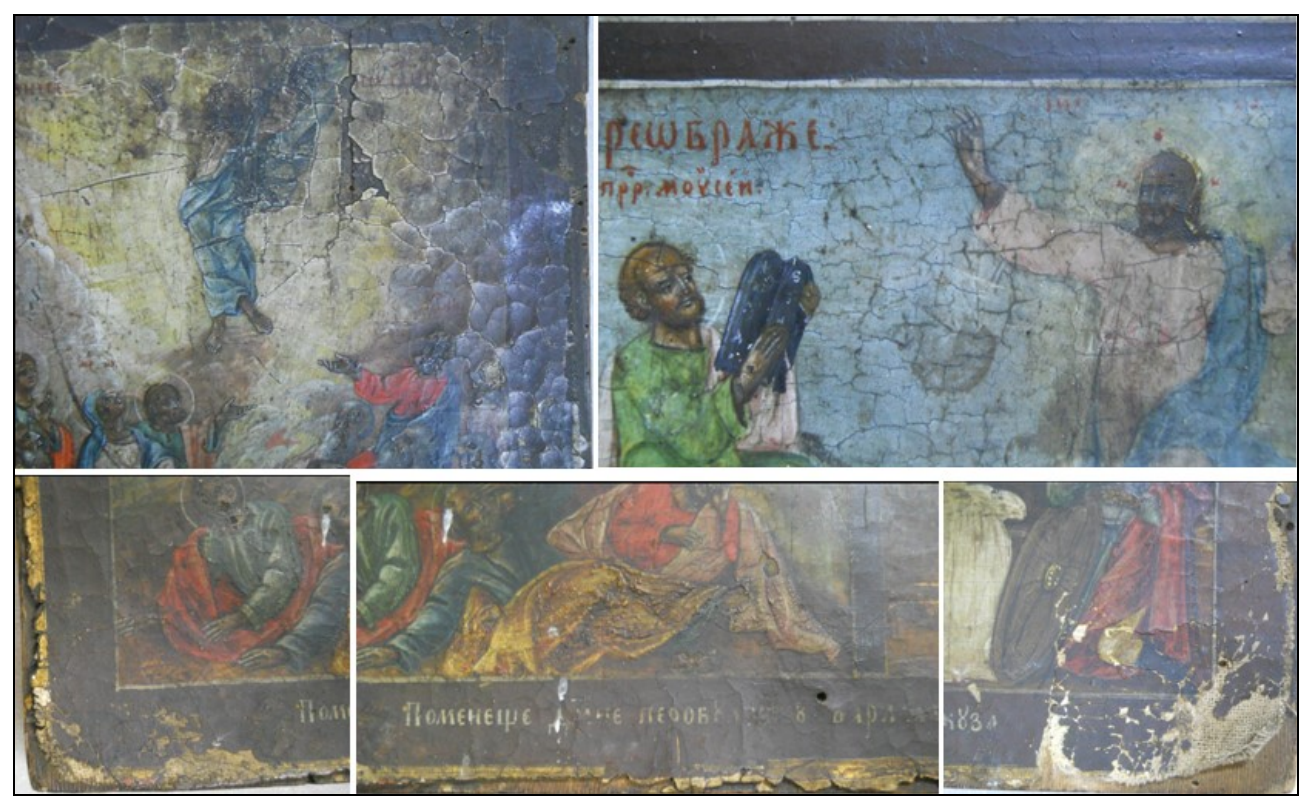

Fig. 2. Details from the four registers of the Pentecost icon:

blackening, clogged varnish, dirt, clogged structure, cracks, burns, iridescent areas;

The second icon represents the patron of Dobrovăţ monastery, Pentecost. The icon, painted in four registers (Fig. 1b), has long been exposed liturgical worship rituals and now has a high degree of deterioration/degradation accumulated over time as a thick layer of dust, dirt, insect excrements, smoke from candles, lipstick, drops of tears, wax, fat traces from human hands etc., which have interacted with 
varnish and transformed through oxidation in dark degradation products, shrunken, often called clogged or vesicant structure. Unfavorable weather conditions (moisture, heat, light from candles sometimes kept to close) have emphasized degradation, leading to multiple cracks all over the painting layer, detachments and materials loss, bruises, burns, blisters, iridescent spots, scale-shaped pieces etc. The icon presents a thick layer of ground from animal glue and the canvas used is handmade. The painting is done in egg tempera, with colored earth pigments ochre, green, blue, vermillion ( $\mathrm{HgS})$, white chalk and ivory black, with gold leaf on the narrow frame of the icon and egg emulsion as binder. The thick varnish layer in colophony based. From a religious point of view, the icon symbolizes the four Christian holidays: Jesus talking with the disciples before the crucifixion, Resurrection, Ascension and Pentecost.

The UV, IR and visible reflectography studies the current state of the two icons and they shown areas from the painting layer that are affected by deterioration/degradation, clogged dust and dirt deposits, a dark glossy appearance painting layer, a clouded varnish film, low readability, yellowed colors, aged and changed pigments, losses from the painting layer and support (Fig.1.a b).

\section{Cleaning systems, cleaning tests.}

The use of cleaning tests is mandatory, because during the cleaning process can affect the integrity of the noble patina and that of other degraded polychrome layers, which can be easily washed away. There is also always the risk of exudates, of a degreasing mation color process, new crack, peeling off the painting layer and losses of material etc. The icons undertook some cleaning tests with cotton pads $(100 \%)$ (Fig.3 a, b), wrapped on wooden skewers, and then soaked in solutions or mixtures of various solvents. Cleaning test with the standard solution E2 and with other noninvasive ecological solution systems was done on several areas with similar conservation state. Each area was first wetted, after which it was successively cleaned on a perpendicular direction for at least three minutes. The cleaning capacity was analyzed, similar to other studies [10,13-21] by the naked eye and also by visible and UV reflectography and CIEL*a*b*reflection colorimetry. The evalution of color changes and of the degree of cleaning was done with the help of LOVIBOND RT Series (Reflectance Tintometer). This allowed the registration of the color deviation directly on the sample, before and after washing. The data was then transferred to a computer and processed. For cleaning test on the gold leaf on the embroided carved wood from the XVIII-th century icon (Ascension of the Virgin Mary into Heaven) simple or mixt organic pigments were used as followed:: (E1-E10) (Fig.4);

E1 - dichloroethane;

E2 - alcohol, turpentine; 
E3 - alcohol, cyclohexane, turpentine;

E4 - turpentine;

E5 - cyclohexane;

E6 - alcohol;

E8 - Contrad;

E9 - xylene;

E10 - alcohol, xylene;

For the polychrome layer of the Pentecost icon:
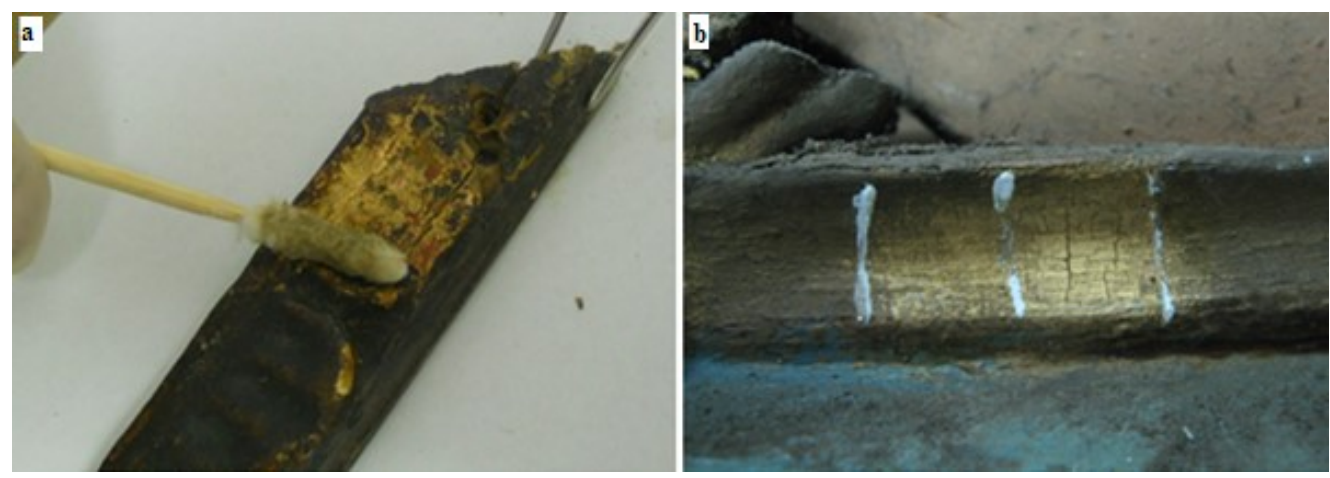

Fig. 3. Cleaning test

a) The white garment (Jesus shirt), ( Fig. 6 a).

E1-concentrated alcoholic solution $(6 \mathrm{~mL}$ ethanol, $6 \mathrm{~mL}$ of distilled water, ammonia 3 drops);

E2-6mL of concentrated alcoholic solution resulted from $(6 \mathrm{~mL}$ ethanol, 6 $\mathrm{mL}$ of distilled water, ammonia 3 drops) with $3 \mathrm{~mL}$ of the obtained egg (egg yolk and $2 \mathrm{~mL} 2 \mathrm{~mL}$ distilled water);

Noninvasive ecological systems (S1, S6) (Fig. 6a) for old tempera were also used, made like simple, binary and ternary aqueous dispersion, following these recipes:

S1-corn silk infusion (Zea mays), obtained by boiling $10 \mathrm{~g}$ of corn silk from inside the corn, in $200 \mathrm{~mL}$ of distilled water, for $5 \mathrm{~min}$;

S2-20 mL mature carrot colorless juice (Daucus carota L.) (separated by centrifugation, filtration and tailings);

S3-20 mL dispersed binary system, corn silk tea*: colorless carrot juice*=1: 1;

S4-20 mL dispersed binary system, colorless acacia infusion*: parsley colorless juice $=1: 1$;

S5-20 mL ternary system, maize silk infusion*: colorless carrot juice*: colorless parsley juice $=1: 1: 1$; 
S6- acacia colorless tea prepared by boiling in $200 \mathrm{ml}$ of distilled water $10 \mathrm{~g}$ of dried flower acacia, for $5 \mathrm{~min}$.);

b) For the red garment of the Pentecost icon (Fig. 6 b):

absolute alcohol solution in different degrees of concentration (absolute ethyl alcohol and distilled water), (E1, E2); E1. 80\% ethanol and 20\% distilled water;

E2. $90 \%$ ethanol and $10 \%$ distilled water;

Noninvasive ecological systems (S1, S7) (Fig. 6b) for old tempera were also used, made like simple, binary and ternary aqueous dispersion, following these recipes:

S1-Soapwort infusion obtained by boiling in $200 \mathrm{~mL}$ dry Soapwort $10 \mathrm{~g}$ distilled water for $5 \mathrm{~min}$;

S2-corn silk infusion (Zea mays), obtained by boiling $10 \mathrm{~g}$ of corn silk from inside the corn, in $200 \mathrm{~mL}$ of distilled water, for $5 \mathrm{~min}$;

S3-20 mL of mature carrot colorless juice (Daucus carota L.) (separated by centrifugation, filtration and tailings);

S4-20 mL of Soapwort infusion in dispersed binary system*: $20 \mathrm{~mL}$ infusion of corn silk in disperse systems*: $=1: 1$;

S5-20 mL of corn silk infusion in ternary system*: *Soapwort infusion colorless: colorless carrot juice $*=1: 1: 1$;

S6-20 mL of corn silk infusion in binary system*: colorless carrot juice* ${ }^{*}=1: 1$;

S7-20 mL of corn silk infusion in ternary system*: *colorless soapwort infusion: colorless juice Parsley* $=1: 1: 1$;

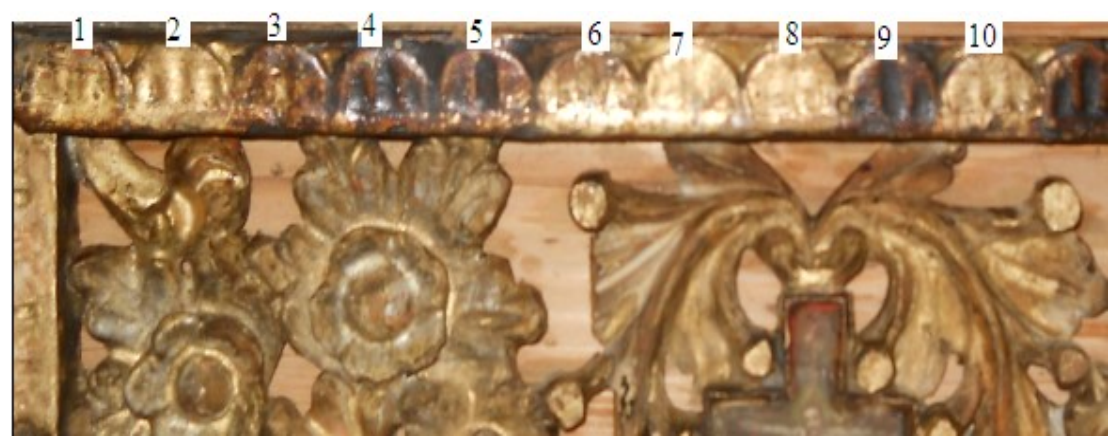

Fig. 4. Cleaning tests for the gold leaf covered carved wood, with simple and mixed solutions (E1, E10)

\subsection{Ascension of the Virgin Mary into Heaven}

After the analysis of the conservation state was finished, the cleaning process of the icon from the XVIII-th century started. First the dust was removed with a brush and a vacuum, and then simple or mixed cleaning solutions were used to remove the dirt on the gold covered polychrome layer, as followed: 
E1 - dichloromethane (8: 1), 12 washes, $5 \mathrm{~min}$, slow dissolution.

E2 - ethyl alcohol, turpentine (1: 1), 3 washes, 4 minutes, good dissolution.

E3 - ethyl alcohol, cyclohexane, white spirit (1: 1: 1), 9 slow washes, 3 minutes.

E4 - turpentine (8: 1), 8 washes, slow dissolution.

E5 - cyclohexane (8: 1), 9 washes, slow dissolution.

E6 - ethanol (7: 1), 7 washes, good dissolution.

E7- Kromofag (commercial solution, based on dichloromethane and methanol) (2: 1), 2 washes.

E8 - Contrad (commercial solution based on $\mathrm{NaOH}),(4: 1), 4$ washes.

E9 - xylene (2: 1), 2 washes, cleansing zero.

E10 - ethyl alcohol, xylene (2: 1), 5 washes.

In order to clean the gold leaf covered carved wood classic organic solvents systems were used, simple or mixed. The most efficient simple systems were: E6, E1, E5, E4, E9. The effectiveness order in the binary systems was this E8, E7, E2, E10, E3, results (8:1:7:4) (Fig. 4) obtained after monitoring the cleaning tests through CIEL*a*b* colorimetry (Fig. 5).

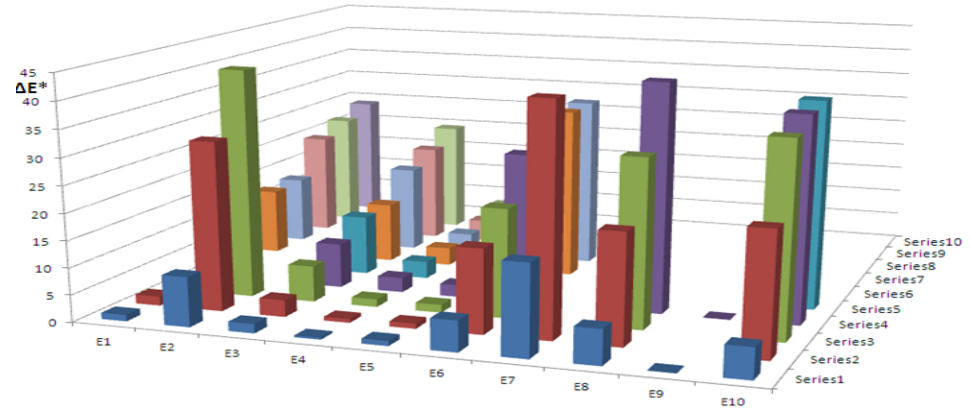

Fig. 5. Cleaning effectiveness by CIEL*a*b* colorimetry, with organic solvents systems: a) simple, solutions (E6, E1); b) binary or ternary, solutions (E8, E7)

The standard solutions for the icon Ascension of the Virgin Mary into Heaven are the following: on the simple systems it was E6, followed by E1, on the binary/ ternary systems, E8, followed by E7. Turpentine its used to diminish the cleaning action of a solvent like ethanol. The mixes of binary and ternary solvents have good results because they inflate the strongly clogged dirt layer. Therefore take into account the basis weight and the concentration used. The cleaning solvent diffusion rate is influenced by their molecular volume and viscosity by comparing their times of swelling in the layer of dirt. The low viscosity such as benzene and acetone produced a more rapid swelling than those with higher viscosity such as 
isopropyl alcohol-boutique. The small molecular volume, such as methanol are producing rapid diffusion and swelling.

\subsection{The Pentecost}

After the analysis of the conservation state was finished, the cleaning process of the Pentecost started. First the dust was removed with a brush and a vacuum, and then simple or mixed cleaning solutions were used to remove the dirt on the gold covered polychrome layer, as followed:

The cleaning of the white garment (Jesus shirt) was done with concentrated alcoholic solution obtained from $(6 \mathrm{~mL}$ ethanol, $6 \mathrm{~mL}$ of distilled water, 3 drops of ammonia) (E1),

$6 \mathrm{~mL}$ concentrated alcoholic solution mixed with $3 \mathrm{ml}$ egg emulsion solution, respectively (E2) and non-invasive organic systems (S1-S6) (Fig. 6) for egg tempera.
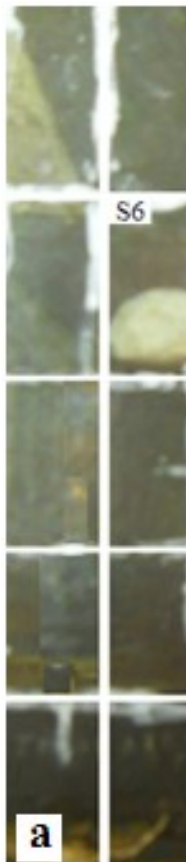
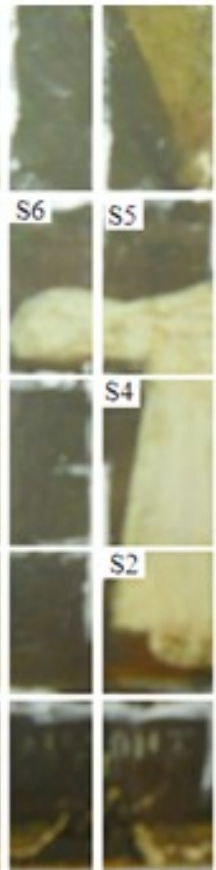
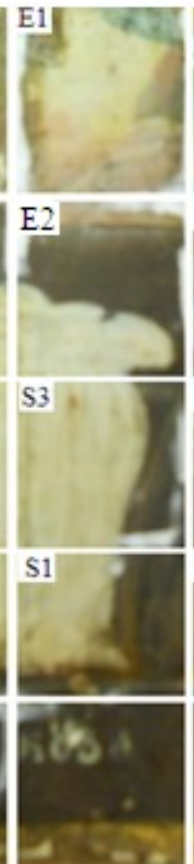
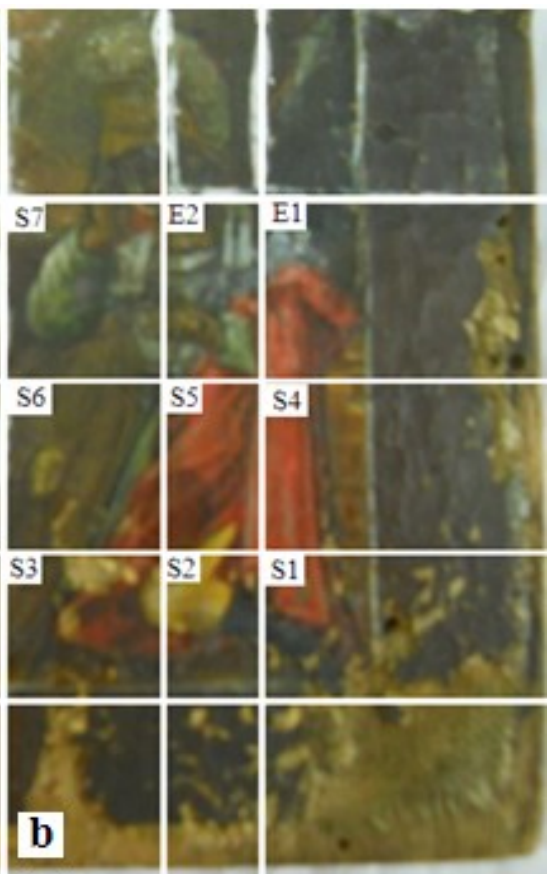

Fig. 6. Cleaning tests: a) the white garment, with concentrated alcohol solution (E1, E2); and noninvasive ecological systems ( S1, S6 ); b) red garment, with alcohol solution (E1, E2); and noninvasive ecological systems ( S1, S7); 
S1-corn silk infusion (Zea mays), obtained by boiling $10 \mathrm{~g}$ of corn silk from inside the corn, in $200 \mathrm{~mL}$ of distilled water, for $5 \mathrm{~min}$;

S2-20 mL mature carrot colorless juice (Daucus carota L.) (separated by centrifugation, filtration and tailings);

S3-20 mL dispersed binary system, corn silk tea*: colorless carrot juice* $=1: 1$;

S4-20 mL dispersed binary system, colorless acacia infusion*: parsley colorless juice $* 1: 1$;

S5-20 mL ternary system, maize silk infusion*: colorless carrot juice*: colorless parsley juice $=1: 1: 1$;

S6- acacia colorless tea prepared by boiling in $200 \mathrm{ml}$ of distilled water $10 \mathrm{~g}$ of dried flower acacia, for $5 \mathrm{~min}$.);

The tests E1 and E2 were applied on the surfaces of two drawn squares on rows 3 and 4 on the icon (Fig. 6), on the white garments (Jesus shirt). This was done in order to compare the cleaning capacity of the two solutions by comparison. The solutions were applied for 2 minutes each, 4 washes for each tests. The cleaning was good, the dust and the dirt were easily solubilized and the clogged layer of dirt was removed.

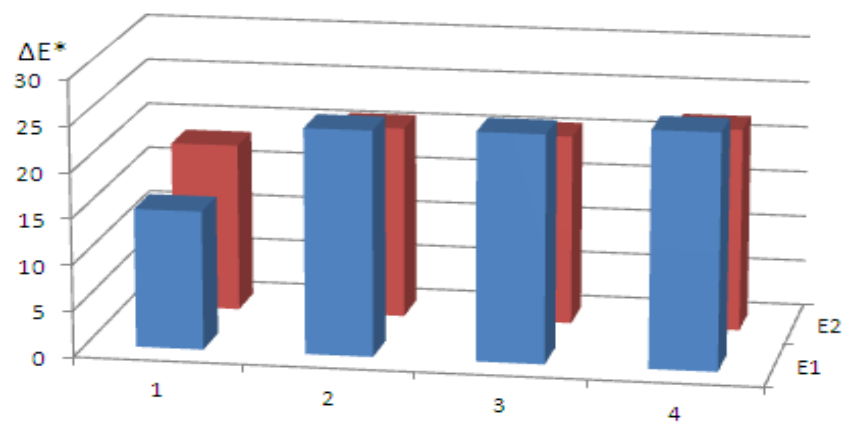

Fig. 7. Cleaning with concentrated alcohol solution (E1, E2)

The noninvasive ecological systems were:

a. Simple solutions $(S 1, S 2, S 6)$

S1- corn silk infusion (Zea mays), obtained by boiling $10 \mathrm{~g}$ of corn silk from inside the corn, in $200 \mathrm{~mL}$ of distilled water, for $5 \mathrm{~min}$;

S2-20 mL mature carrot colorless juice (Daucus carota L.) (separated by centrifugation, filtration and tailings);

S6- acacia colorless tea prepared by boiling in $200 \mathrm{ml}$ of distilled water $10 \mathrm{~g}$ of dried flower acacia, for $5 \mathrm{~min}$.); 


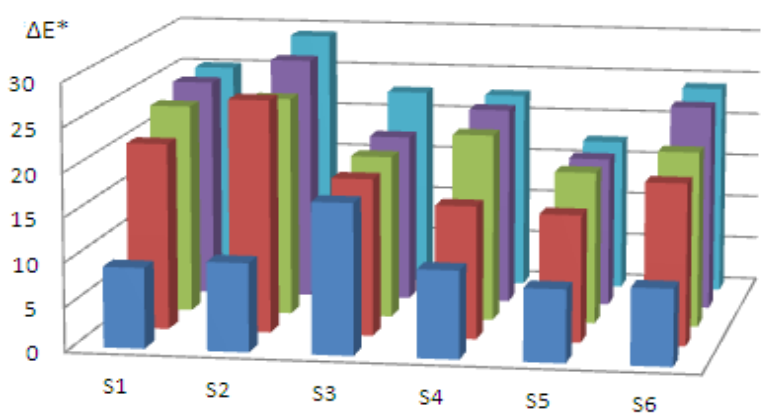

Fig. 8. CIEL*a*b colorimetry: cleaning with noninvasive ecological systems:

a) simple solutions (S1, S2, S6), b) binary (S3 şi S4), ternary ( S5)

\section{a. Binary solutions $(S 3, S 4)$}

S3-20 mL dispersed binary system, corn silk tea*: colorless carrot juice*=1: 1;

S4-20 mL dispersed binary system, colorless acacia infusion *: parsley colorless juice $*=1: 1$;

b. Ternary solutions $S 5$

S5-20 mL ternary system, maize silk infusion*: colorless carrot juice*: colorless parsley juice $=1: 1: 1$;

The cleaning of the red garment with alcohol solutions (E1, E2) and noninvasive ecological systems for old tempera (S1, S7) (Fig. 9):

S1-soapwort infusion obtained by boiling in $200 \mathrm{~mL}$ dry soapwort $10 \mathrm{~g}$ distilled water for $5 \mathrm{~min}$.);

S2-corn silk infusion (Zea mays), obtained by boiling $10 \mathrm{~g}$ of corn silk from inside the corn, in $200 \mathrm{~mL}$ of distilled water, for $5 \mathrm{~min}$;

S3-20 mL of mature carrot colorless juice (Daucus carota L.) (separated by centrifugation, filtration and tailings);

S4-20 mL of Soapwort infusion in dispersed binary system, ${ }^{*}$ : colorless carrot juice $^{*}=1: 1$;

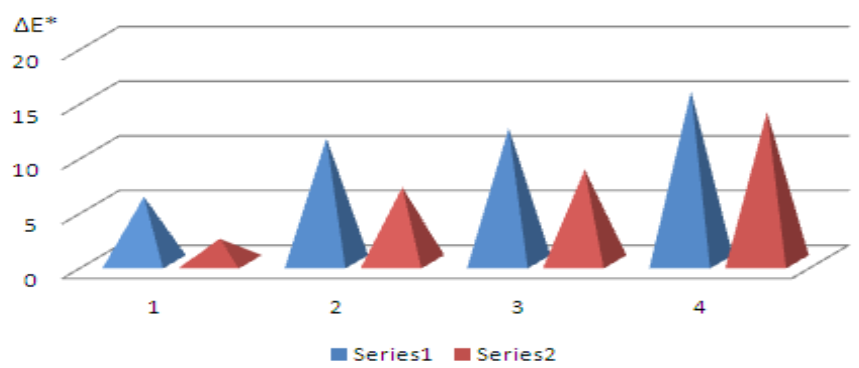

Fig. 9. Cleaning with standard alcohol solution (E1, (E2) 
S5-20 mL of corn silk infusion dispersed in ternary system,*: soapwort colorless infusion*: colorless carrot juice* $=1: 1: 1$;

S6-20 mL of corn silk infusion in binary system, ${ }^{*}$ :colorless carrot juice ${ }^{*}=1$ : 1 ;

S7-20 mL of corn silk infusion dispersed in ternary system, *: $20 \mathrm{ml}$ of colorless soapwort infusion*: colorless parsley juice* $=1: 1: 1$;

The tests E1 and E2 were applied on the squared part of the icon (Fig. 6 b) for 2 minutes and 4 washes for each test. The cleaning was good, the dust and dirt decomposed easily, and the painting layer and pigments weren't affected and didn't interact with the two test solutions used.

The noninvasive ecological systems used were:

a. Simple solutions $S 1$ (soapwort), $S 2$ (corn silk), $S 3$ (carrot);

b. Binary solutions $S 4$ (corn silk and soapwort) $S 6$ (made from corn silk and carrot);

c. Ternary solutions S5 (corn silk, carrot and soapwort), S7 (corn silk, soapwort, parsley);

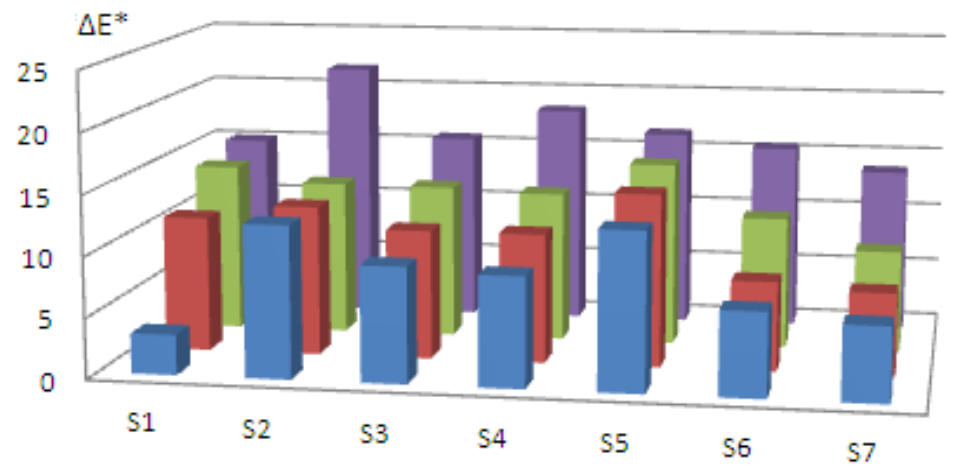

Fig. 10. CIEL*a*b* colorimetry for cleaning with noninvasive ecological systems: a) simple solutions ( 1 1 , S2, S3), b) binary (S4 şi S6), ternary ( S5, S7)

The samples on which the test were done were taken from all four registers (Fig. 11).

Composition data in table 1 confirms the chemical nature of the pigments used in painting the icon, except the egg emulsion based binder and the organic dirt, which is represented by a part of carbon and oxygen composition (the rest comes from carbonates, sulfates, oxides and chemically bound water as crystalhidrates, aquo-and hydroxo complex. The following pigments were identified:

- gold leaf on the frame, mixed with silver and cooper;

- green-cache, obtained by mixing ultramarine blue with yellow litharge or massicot and white lead (PM2);

- red obtained by mixing ultramarine red and red lead; 
- olive green, obtained by mixing the green pigment (ultramarine blue with yellow litharge or massicot and white lead) with lead white - whitewash and barium white - barium sulfate;

- blue, made out of ultramarine blue, with a hint of lead white and barium white;

- lead white, tinted with barium white (barium sulfate) and gypsum dehydrated calcium sulfate;

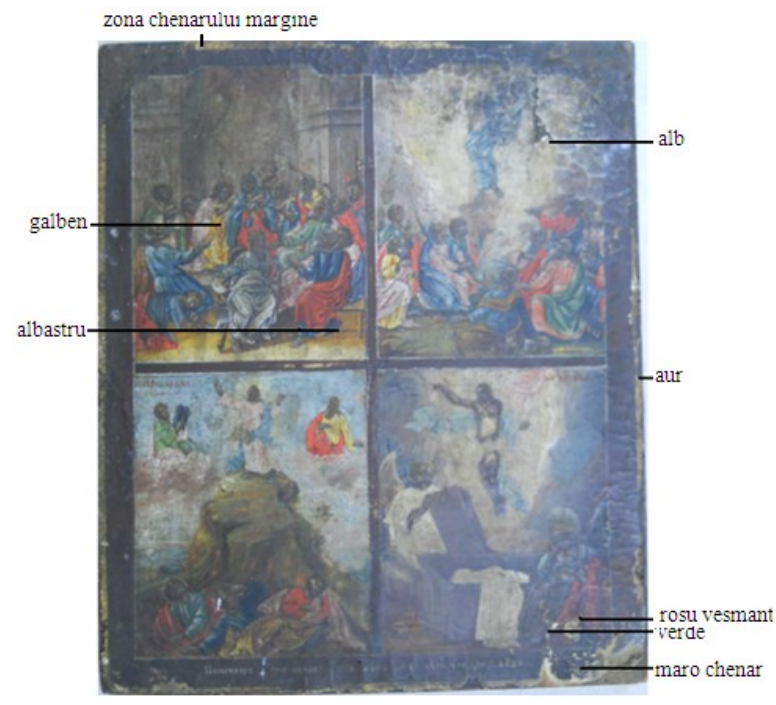

Fig. 11. Samples taken from Pentecost icon

Lead white or whitewash $\left(2 \mathrm{PbCO}, \mathrm{Pb}(\mathrm{OH})_{2}\right)$ is a fine microcrystalline powder with a very good drying capacity, soluble, effervescing $\mathrm{CO}_{2}$. The high composition of $\mathrm{C}$ and $\mathrm{O}$ that is the painting layer is due to the clogged dirt. The blue pigment is natural mineral, with shining, light blue micro crystals, obtained by combining natural and artificial ultramarine $\left(\mathrm{Na}_{8-10} \mathrm{Al}_{6} \mathrm{Si}_{6} \mathrm{O}_{24} \mathrm{~S}_{2-4}\right)$ and Prussian blue $\left(\mathrm{Fe}\left[\mathrm{Fe}^{3+} \mathrm{Fe}^{2+}(\mathrm{CN})_{6}\right]_{3}\right)$. This pigment is easily soluble, effervescing $\mathrm{H}_{2} \mathrm{~S}$, it doesn't react (if it reacts, the processes is really slow, the color slowly changing from blue to pale yellow). The blue pigment used on the back of the icon is also a natural mineral, made out of the same two pigments, ultramarine blue and Prussian blue, but with a different ratio. The analysis of the sample taken from the golden area of the icon has proven that the metallic yellow leaf used by the author is made out of gold, silver and cooper. The litharge (lead oxide, $\mathrm{PbO}$ ), used to paint the yellow garments, is obtained by slightly heating lead white and then melting the metallic lead in open space. The difference between litharge and massicot is just physical: 
the litharge has a crystalline structure, while the massicot is amorphous. The red pigment used is minium lead, $\left(\mathrm{PbO}_{2 \cdot 2} \mathrm{PbO}\right)$, also called lead red or Saturn red. This pigment is obtained by heating whitewash $(\mathrm{PbO})$ at $4800{ }^{\circ} \mathrm{C}$. It has a good coloring power, extra smooth and can be in a crystalline structure or amorphous, depending on the way it's made. It has a high specific weight $(8,8.9)$ and an elevated

Table 1. SEM-EDX results on the samples taken from Pentecost icon

\begin{tabular}{|c|c|c|c|c|c|c|c|c|c|c|c|c|c|c|c|c|c|}
\hline \multirow{2}{*}{$\begin{array}{l}\text { Nr. } \\
\text { probei }\end{array}$} & \multicolumn{17}{|c|}{ Compozitia elementală in procente gravimetrice } \\
\hline & $\mathrm{Si}$ & Al & $\mathrm{Fa}$ & $\mathrm{Pb}$ & $\mathrm{Ca}$ & $\mathrm{Mg}$ & $\mathrm{Cu}$ & $\mathrm{Cl}$ & $\mathrm{Na}$ & $\mathrm{Ti}$ & $\mathrm{K}$ & $\mathrm{Ph}$ & S & Au & $\mathrm{Ag}$ & C & 0 \\
\hline $\mathrm{Alb}$ & 0,622 & 0,405 & . & 12,581 & 1,092 & 0,333 & . & . & 0,549 & - & 0,193 & . & . & - & - & 17,638 & 66,584 \\
\hline $\begin{array}{l}\text { A } \\
\text { lbastru }\end{array}$ & 2,412 & 1,491 & 1,135 & 11,845 & 2,442 & 0,185 & & & . & . & 0,821 & 0,476 & 1,133 & - & - & 16,566 & 61,488 \\
\hline $\begin{array}{l}\text { Alba. } \\
\text { Vers. }\end{array}$ & 1,943 & 1,634 & 0,693 & 6,897 & 0,920 & 0,604 & - & . & - & . & 0,473 & 0,446 & 2,814 & - & - & 18,083 & 65,487 \\
\hline $\begin{array}{l}\text { Aur } \\
800 \times b 5 \\
\text { a }\end{array}$ & 2,358 & 1,105 & 1,599 & 6,173 & 3,467 & 0,199 & 0,358 & - & 0,225 & - & 1,244 & . & 1,055 & 4,584 & 0,713 & 14,889 & 62,024 \\
\hline $\begin{array}{l}\text { Aur } \\
917 \times \text { se, }\end{array}$ & 2,150 & 0,818 & 1,815 & 8,467 & 1,453 & 0,080 & 0,547 & . & 0,083 & . & 0,623 & - & 0,607 & 11,302 & 0,642 & 17,378 & 54,030 \\
\hline $\begin{array}{l}\text { Chenar } \\
\text { sus }\end{array}$ & 4,599 & 5,545 & - & - & 1,319 & 4,185 & . & . & 8,804 & . & - & . & $\begin{array}{r}6,623 \\
=\end{array}$ & - & - & 18,222 & 50,699 \\
\hline $\begin{array}{l}\text { Galb } \\
914 x\end{array}$ & 0,304 & 0,323 & - & 12,789 & 0,217 & . & - & - & . & . & - & . & 0,545 & - & . & 21,547 & 64,272 \\
\hline $\begin{array}{l}\text { Galb91 } \\
5 \mathrm{xjpg}\end{array}$ & 0,091 & 0,748 & - & 12,251 & 0,280 & - & - & - & - & - & - & - & - & - & - & 17,790 & 68,838 \\
\hline $\begin{array}{l}\text { Galb91 } \\
6 \times j p g\end{array}$ & . & 0,238 & . & 3,944 & 18,287 & 0,067 & - & - & . & . & - & . & - & . & - & 9,663 & 67,799 \\
\hline $\begin{array}{l}\text { Galb.1 } \\
000 \mathrm{cul}\end{array}$ & 4,060 & 2,455 & 0,733 & 5,477 & 2,269 & 1,202 & . & & 2,046 & . & 0,748 & 0,517 & 0,609 & . & . & 16,354 & 63,534 \\
\hline $\begin{array}{l}\text { Maro } \\
\text { chenar }\end{array}$ & 6,957 & 4,387 & 0,949 & - & 3,062 & 2,528 & - & 0,656 & 4,436 & . & 0,992 & 1,000 & 2,087 & - & - & 14,094 & 58,845 \\
\hline Rosu & 8,302 & 4,427 & 1,057 & - & 2,467 & 2,310 & - & 0,754 & 2,908 & - & 1,986 & 1,384 & 3,198 & - & - & 11,663 & 59,539 \\
\hline Verde & 11,058 & 9,340 & 0,913 & 5,84 & 5,003 & 5,575 & - & 1,634 & 8,006 & 0,906 & 2,293 & 2,688 & 3,080 & . & . & \begin{tabular}{|l|}
11,767 \\
\end{tabular} & 31,888 \\
\hline
\end{tabular}

refractive index $(2,46)$ and a very low resistance to concentrated acids and bases. Also, it's not stable when exposed to light and air (it tends to transform into dark brown lead dioxide $\left(\mathrm{PbO}_{2}\right)$, phenomenon often seen on wall paintings in Romania. It is compatible with all pigments, even sulfate based ones, if those don't contain free sulfides. By corroborating these data with the ones obtain through FTIR spectroscopy (Fig. 6 and Table 1), the pigments, the egg emulsion binder and Dammar resin based were confirmed, alongside with the organic deposits (fat from hands, wax from candles, oil). The ground was identified as a thin layer of brown bolus, which contains minium lead mixed either with earth white and calcium carbonate, barium sulfate/carbonate or with barium sulfate and calcium. The ivory black pigment $(\mathrm{C})$, used for shadows, black strokes and borders, can be found in all 
9 samples, under the dirt deposits. The protocol for choosing the icons for this study took into consideration the fact that in evaluation of the cleaning quality of the new water based systems, prepared according to the experiment, it is absolutely necessary to exist a series of surfaces with similar distributed and clogged dirt and similar painting materials used (in this case, earth colored pigments, egg based binder and Dammar resin based varnish). The painting layer of the icon was done using a wide range of pigments across all registers, pigments used by old icon painters between XVII - XIX centuries, in the east - European byzantine space. Because the icons have poor conservation state, they were removed from the liturgical circuit. Once stored, due to improper climate conditions, through oxidation, the dust and dirt have become clogged. This fact, with the unevenness of the deposits on the polychrome layer and on the wooden support, has allowed the differentiated evaluation of cleaning effectiveness for each of the three systems taken into study: simple, binary and ternary.

\section{Results and discussions}

After applying the washing test on each icon, visual observations with the magnifying glass were done, by comparing with the adjacent surfaces. On the XVIII-th century icon, Ascension of the Virgin Mary into Heaven, which has a thicker layer of clogged dirt and its older, were tested the organic solvents based systems, known in literature for cleaning oil painting. The usage of ecological systems wasn't possible due to the age patina and the higher degree of dehydration.

Next, the results of the simple, binary and ternary systems tests are presented, alongside with the results of the tests for alcohol solution (different concentrations) and those of a optimum mix of organic solvents, often used for cleaning oil paintings:

Test E1 - dichloromethane (8: 1), 12 washes, $5 \mathrm{~min}$ and slow dissolution.

Test E2 - ethyl alcohol, turpentine (1: 1), 3 washes, for 4 minutes, good dissolution.

Test E3 - ethyl alcohol, cyclohexane, white spirit (1:1:1), 9 slow washes, 3 minutes.

Test E4 - turpentine (8: 1) to eight washes, 5 minutes, slow dissolution.

Test E5 - cyclohexane (8: 1), 9 washes, slow dissolution.

Test E6 - ethanol (7: 1), seven washes, 5 minutes, good dissolution.

Test E7 - Kromofag (based commercial solution of dichloromethane and methanol) (2: 1), 2 washes.

Test E8 - Contrad (commercial solution based on $\mathrm{NaOH}$ ), (4: 1), 4 washes.

Test E9 - xylene (2: 1), 2 washes, cleansing zero.

Test E10 - ethyl alcohol, xylene (2: 1), 5 washes, good solubilizing, 3 minutes. 
For the second icon, XIX-th century Pentecost icon, with the four registers in egg tempera, simple or mixed organic solvents bases systems (E1, E2) were used in corroboration with alcohol solution in different concentrations (E1, E2), and noninvasive ecological systems (simple, binary, ternary) freshly made for egg tempera.

The classic, simple or mixed solutions or alcohol and distilled water, in various concentrations, have an effective action against the thick clogged dirt layer. The cleaning was easy, the pigments and the binder didn't interact with the solutions and no other deteriorations and degradations occurred. The noninvasive ecological systems (simple, binary and ternary) freshly made, for egg tempera, known in literature for cleaning old tempera paintings, are slower in the dissolution of the layer of clogged dirt and the cleaning is easier for the dust and for the dirt with no adherence. These solutions are effective because they don't deteriorate or degrade the painting or the polychrome layer and are not toxic for the object or for the curator.

\section{Conclusions}

The evaluation of cleaning effectiveness on the two icons, one from XVIII-th century and the other, from the XIX-th century, done by using simple or mixed organic solvents systems and noninvasive ecological systems, was done with the naked eye and through UV-VIS reflectography and CIEL*a*b* colorimetry. The quality of the cleaning process with simple and mixed organic solvents systems on the gold leaf of the icon Ascension of the Virgin Mary into Heaven was tested accordingly to the decreasing values of $\Delta \mathrm{E}^{*}$. For the simple systems is: E6, E1, E5, E4, E9 and for the binary systems is E8, E7, E2, E10, E3. The standard cleaning solutions for the icon Ascension of the Virgin Mary into Heaven were E6 and E8.

The cleaning quality of the concentrated alcohol solution systems was tested accordingly with the decreasing $\Delta \mathrm{E}^{*}$ values. So, for simple systems are E6, E1, E5, E4, E9 and for binary systems are E8, E7, E2, E10 and E3. The standard solution for cleaning the second icon, Pentecost, is E2. The cleaning efficiency for the white garments of noninvasive ecological systems was determined by testing accordingly with the decreasing values of $\Delta \mathrm{E}^{*}$ for simple solutions (S2, S1, S6), for binary solutions (S3, S4) and for ternary solution (E5).the standard solutions of noninvasive ecological systems for the same icon are S2 for simple solutions, S3 for binary ones and S5 for ternary ones. The cleaning effectiveness on the red garment (Pentecost icon) of concentrated alcohol solution systems was tested accordingly with the decreasing value of $\Delta \mathrm{E}^{*}$, as followed E2 and E1. The standard solution for cleaning this garment is E2. 
The cleaning efficiency of the old varnish on the red garment was tested accordingly with the decreasing value of $\Delta \mathrm{E}^{*}$ for simple solutions (S2, S1, S3) for binary solutions (S4, S6) and (E5, S7). The standard solutions for the same icon are: S2, for simle solutions, S4 for binary solutions and S5 for ternary solutions.

\section{References}

Brandi, C. (1997), Teoria del restauro, Edizioni di Storia e Letteratura (Einaudi T, editor), Roma.

Calvo, A. (2002), Conservación y restauración de pintura sobre lienzo, Ed. del Barcelona, Serbal.

Domingues J., Bonelli N., Giorgi R., Fratini E., Baglioni P. (2013), Innovative method for the cleaning of water-sensitive artifacts: Synthesis and application of highly retentive chemical hydrogels. Internat. Journal of Conservation Science, 4, 715-722.

Khandekar, N. (2000), A survey on the conservation literature relating to the development of acqueous gel cleaning on painted and varnished surfaces, Rev. Conserv., 1, 10-20.

Mills J.S., White R. (1994), The Organic Chemistry of Museum Objects. ButterworthHeinemann, London.

Pouli P., Emmony D.C., (2000), The effect of $N d$ : YAG laser radiation on medieval pigments, Journal of Cultural Heritage, 1, S181-S188.

Pruteanu S., Sandu I., Vasilache V., Gherman L.G., Sandu I.C.A., Cristache R.A. (2013), Integrated Analytical Study for the Evaluation of Cleaning Effectiveness on Old Wood Romanian Icons, PRO LIGNO, 9, 242-250.

Pruteanu S., Gherman L.G., Sandu I., Hayashi M., Cozma D.G., Vasilache V., Sandu I.C.A., (2013), Ecological Materials Used in Preservation and Restoration on New Wood, PRO LIGNO, 9, 265-275.

Teixeira, S.J.V., (2011), Hidrólise Enzimática das Proteinas da Dreche, Master Thesis, University in Porto, Porto.

Sandu I.C.A., Luca C., Sandu I., (2000), Study on the compatibility between the old artistic techniques and the new materials and methods for the conservation Restauration processes inventations. I. Theoretical aspects, Revista de Chimie (Bucharest), 51, 532-542.

Sandu, I.C.A., Luca, C., Sandu, I., Pohonţu M.., (2001a), Research regarding the soft wood support degradation evaluation in old paintings, using preparation layers. II. IR and FTIR Spectroscopy, Revista de Chimie (Bucharest), 52, 409-419.

Sandu, I.C.A., Luca C., Sandu, I., Atyim, P. (2001b), Research regarding the soft wood support degradation evaluation in old paintings, using preparation layers. 1. Chemical composition and technical analysis, Rev.de Chimie (Bucharest), 52, 46-52.

Sandu, I., Luca, C., Sandu, I.C.A., Ciocan, A., Suliteanu, N., (2001c), A study on the compatibility of the old, traditional artistical techniques with the new materials and methods used in the restauration, preservation processes. II - A chromatic analysis, Revista de Chimie (Bucharest), 52, 485-490. 
Sandu I.C.A., Bracci S., Sandu I., (2006), Instrumental analyses used in the authentification of old paintings - I. Comparison between two icons of XIXth century, Revista de Chimie (Bucharest), 57, 796-802.

Sandu I., Luca C., Sandu I.C.A., Vasilache V., (2007), Old paintings authentication through the identification of the polychrome layers materials - I. Gas-cromatography analyse, Revista de Chimie (Bucharest), 58, 879-866.Sandu, I.C.A., Vasilache, V.,

Sandu, I., Luca, C., (2008a), Authentication of the Ancient Easel-paintings through Materials Identification from the Polychrome Layers III. Cross - section Analysis and Staining Test, Revista de Chimie (Bucharest), 59, 855-886.

Sandu, I.C.A., Luca, C., Sandu, I., Vasilache, V., Hayashi, M., (2008b), Authentication of the ancient easel paintings through materials identification from the polychrome layers - II. Analysis by means of the FT-IR spectrophotometry, Revista de Chimie (Bucharest), 59, 384-387

Sandu I.C.A., Bracci S., Sandu I., Loberfaro M., (2009), Integrated Analytical Study for the Authentication of Five Russian Icons (XVI-XVII centuries, Microscopy Research and Technique, 72, 755-765.

Sandu I.C.A., de Sa M.H., Pereira M.C., (2011a), Ancient 'gilded' art objects from European cultural heritage: a review on different scales of characterization, Surface and Interface Analysis, 43, 1134-1151.

Sandu I.C.A., Busani T., de Sa M.H., (2011b), The surface behavior of gilding layer imitations on polychrome artefacts of cultural heritage, Surface and Interface Analysis, 43, 1171-1181.

Sandu I.C.A., Murta E., Veiga R., Muralha V.S., Pereira M., Kuckova S., Busani T., (2013), An innovative, interdisciplinary, and multi-technique study of gilding and painting techniques in the decoration of the main altarpiece of Miranda do Douro Cathedral (XVII-XVIIIth centuries, Portugal), Microscopy Research and Technique, 76, 733-743. 